\title{
Incremento de la expresión de Bax (proapoptótico) y disminución de la expresión de Bcl-2 (antiapoptótico) en recién nacidos con enterocolitis necrosante
}

\author{
Increase in pro-apoptotic Bax expression and decrease in anti-apoptotic Bcl-2 \\ expression in newborns with necrotizing enterocolitis
}

\author{
Dr. Ufuk Ates ${ }^{a}$, Dra. Gulnur Gollu ${ }^{a}$,Dra. Gonul Kucuk ${ }^{a}$,Dra. Deniz Billur ${ }^{b}$,Dra. Meltem Bingol-Kologlu ${ }^{a}$, \\ Dr. Yavuz Yllmaz ${ }^{c}$, Dra. Hulya Ozkan-Ulu ${ }^{c}$, Dra. Pinar Bayram ${ }^{b}$, Dr. Emin Bagriacik y Dr. Huseyin Dindar ${ }^{a}$
}

\section{RESUMEN}

Antecedentes/Objetivo: El objetivo de este estudio fue determinar si se producía un incremento de la expresión de Bax (proapoptótico) y una disminución de la expresión de Blc2A1 (antiapoptótico) en el intestino de los recién nacidos con enterocolitis necrosante.

Materiales y métodos: Comparamos a ocho pacientes recién nacidos de manera consecutiva sometidos a resección intestinal debido a enterocolitis necrosante con ocho recién nacidos sometidos a resección intestinal debido a atresia ileal. La evaluación histopatológica de la lesión tisular y la apoptosis se realizó mediante microscopía óptica y el método TUNEL. El nivel de ARNm en los genes apoptóticos (CASP3, CASP6, CASP7, Bax, BIRC2) y antiapoptóticos se evaluó con el método de matriz de RCP (PCR array). La expresión de proteínas se evaluó mediante inmunohistoquímica.

Resultados: Los puntajes de las lesiones tisulares y los puntajes medios de apoptosis fueron significativamente más altos en el grupo con enterocolitis necrosante en comparación con el grupo de referencia $(p<0,01)$. La expresión delos genes proapoptóticos aumentó significativamente en el grupo con enterocolitis necrosante frente al grupo de referencia $(p<0,01)$. La expresión del gen Bcl-2A1 (antiapoptótico) disminuyó significativamente en el grupo con enterocolitis necrosante $(p<0,01)$. La expresión de las proteínas Bax y CASP3 aumentó significativamente en el grupo con enterocolitis necrosante $(p<0,01)$.

Conclusión: Según nuestros datos, la alteración del equilibrio entre la expresión de Bax (proapoptótico) y la expresión de Bcl-2A1 (antiapoptótico) en el lugar de la lesión es un posible mecanismo de la patogenia en recién nacidos que presentan enterocolitis necrosante.

Palabras clave:apoptosis, expresión génica, enterocolitis necrosante, recién nacido.

http:/ / dx.doi.org/10.5546/aap.2016.243

a. Escuela de Medicina de Ankara Üniversitesi, Departamento de Cirugía Pediátrica, Ankara, Turquía.

b. Escuela de Medicina de Ankara Üniversitesi, Departamento de Histología y Embriología, Ankara, Turquía.

c. Educación para la Salud de la Mujer y Hospital de Investigación Zekai Tahir Burak, Departamento de Cirugía Pediátrica, Ankara, Turquía.

d. Escuela de Medicina de Gazi Üniversitesi, Centro de Investigación en Inmunología, Ankara, Turquía.

Correspondencia: Dr. Ufuk Ates: drufukates@gmail.com

Financiamiento: Ninguno.

Conflicto de intereses: Ninguno que declarar.

Recibido: 10-12-2015

Aceptado: 24-2-2016

\section{INTRODUCCIÓN}

La enterocolitis necrosante (ECN) es una afección multifactorial complicada en los recién nacidos y los lactantes prematuros, con una tasa de morbimortalidad elevada en esta población. La enterocolitis necrosante se caracteriza por apoptosis del epitelio intestinal, necrosis, hemorragia, migración incompleta de los enterocitos y proliferación, y produce una falla persistente de la barrera intestinal, que a su vez resulta en la pérdida de la integridad del epitelio, la invasión bacteriana de los intestinos seguida de una reacción inflamatoria hiperreactiva aguda y la consecuente necrosis intestinal. ${ }^{1,2}$

El equilibrio entre la proliferación y la pérdida celular es necesario para conservar la homeostasis del epitelio intestinal. ${ }^{3,4}$ La mayor parte de la pérdida celular en el intestino normal se produce mediante apoptosis. ${ }^{3}$ El equilibrio entre las proteínas proapoptóticas y antiapoptóticas es fundamental para la supervivencia celular. ${ }^{3}$ La familia de proteínas Bcl-2 constituye una clase significativa de moléculas que controlan la apoptosis de los enterocitos. ${ }^{3} \mathrm{Bcl}-2 \mathrm{~A} 1$ es una proteína antiapoptótica que inhibe la liberación del citocromo $c$ desde la mitocondria y revierte los efectos de la proteína Bax proapoptótica. ${ }^{3}$ Se ha demostrado que la apoptosis epitelial exagerada en el intestino produce una lesión grave por enterocolitis necrosante. ${ }^{2,3,5}$ En un modelo de enterocolitis necrosante en ratas, se demostró un incremento de la expresión de los genes apoptóticos simultáneo a la disminución de los genes antiapoptóticos. Además, se ha indicado que la prevención y reducción de la apoptosis en entornos de investigación reducen la incidencia de enterocolitis necrosante. ${ }^{5-7}$ Por lo tanto, apuntamos a descubrir si se produce un incremento de la expresión de los genes proapoptóticos y una disminución de la expresión de los genes antiapoptóticos en el intestino de los recién nacidos con enterocolitis necrosante grave y en comparación con el intestino de los recién nacidos con atresia ileal. En particular, nos centramos en la expresión de los genes 
Bax y caspasa-3 (proapoptóticos) y Bcl -2A1 (antiapoptótico).

\section{MATERIALES Y MÉTODOS}

El comité de ética de la Escuela de Medicina de la Ankara Üniversitesi aprobó la recolección de muestras quirúrgicas con fines investigativos (protocolo número 13-271). El estudio se llevó a cabo de conformidad con la declaración de Helsinki. Se obtuvo el consentimiento informado de los padres para realizar la investigación. Comparamos a ocho pacientes recién nacidos sometidos a resección intestinal debido a enterocolitis necrosante con ocho recién nacidos sometidos a resección intestinal debido a atresia ileal. El aire libre y el gas en el sistema venoso portal observados en las radiografías directas, junto con el deterioro clínico durante el control médico óptimo fueron los criterios para la exploración quirúrgica de los recién nacidos con enterocolitis necrosante. El diagnóstico de enterocolitis necrosante se confirmó durante la investigación patológica de rutina. Se obtuvieron segmentos de $1 \mathrm{~cm} \times 1 \mathrm{~cm}$ de las piezas quirúrgicas durante la laparotomía, que se dividieron en dos partes. Una de las partes se ultracongeló en nitrógeno líquido a $-80{ }^{\circ} \mathrm{C}$ para someterla a una reacción en cadena de la polimerasa (RCP); la otra se conservó en formaldehído para la posterior evaluación histopatológica. La evaluación histopatológica de la lesión tisular se realizó mediante microscopía óptica y asignación de un puntaje al grado de lesión tisular. La evaluación histopatológica de la apoptosis se realizó mediante el método TUNEL (marcado del extremo libre por desoxi-transferasa terminal con isotiocianato de fluoresceína). ${ }^{2,8}$ Los niveles de ácido ribonucleico mensajero (ARNm)

TABla 1: Características clínicas, puntaje de lesión tisular y de apoptosis de los pacientes del grupo con enterocolitis necrosante

\begin{tabular}{|c|c|c|c|c|c|c|c|c|}
\hline \multicolumn{2}{|c|}{$\begin{array}{ll}\text { NEC } & \text { Sexo } \\
\text { group } & \\
\text { Patients } & \end{array}$} & $\begin{array}{c}\text { Edad } \\
\text { gestacional } \\
\text { (en semanas) }\end{array}$ & $\begin{array}{c}\text { Edad al } \\
\text { momento de } \\
\text { la cirugía } \\
\text { (en días) }\end{array}$ & $\begin{array}{c}\text { Peso } \\
\text { (en gramos) }\end{array}$ & $\begin{array}{c}\text { Nivel de compromiso } \\
\text { intestinal } \\
\text { al momento de } \\
\text { la cirugía }\end{array}$ & $\begin{array}{l}\text { Procedimiento } \\
\text { quirúrgico }\end{array}$ & $\begin{array}{c}\text { Puntaje } \\
\text { del grado de } \\
\text { lesión tisular }\end{array}$ & $\begin{array}{c}\text { Puntaje de } \\
\text { apoptosis }\end{array}$ \\
\hline 1 & Masculino & 30 & 20 & 1250 & $\begin{array}{l}\text { Necrosis intestinal } \\
\text { de } 15 \mathrm{~cm}\end{array}$ & $\begin{array}{l}\text { Resección del íleon } \\
\text { e ileostomía }\end{array}$ & 3 & 3 \\
\hline 2 & Femenino & 25 & 7 & 760 & $\begin{array}{c}\text { Necrosis intestinal } \\
\text { de } 25 \mathrm{~cm} \text { y perforación }\end{array}$ & $\begin{array}{c}\text { Resección ileocólica } \\
\text { e ileostomía }\end{array}$ & 4 & 4 \\
\hline 3 & Femenino & 32 & 15 & 1530 & $\begin{array}{c}\text { Necrosis intestinal } \\
\text { de } 30 \mathrm{~cm} \text { y perforación }\end{array}$ & $\begin{array}{c}\text { Resección ileocólica } \\
\text { e ileostomía }\end{array}$ & 4 & 4 \\
\hline 4 & Masculino & 27 & 17 & 850 & $\begin{array}{c}\text { Necrosis intestinal } \\
\text { de } 20 \mathrm{~cm} \text { y perforación }\end{array}$ & $\begin{array}{c}\text { Resección ileocólica } \\
\text { e ileostomía }\end{array}$ & 3 & 4 \\
\hline 5 & Masculino & 33 & 11 & 1600 & $\begin{array}{c}\text { Necrosis intestinal } \\
\text { de } 35 \mathrm{~cm} \text { y perforación }\end{array}$ & $\begin{array}{c}\text { Resección ileocólica } \\
\text { e ileostomía }\end{array}$ & 4 & 4 \\
\hline 6 & Masculino & 31 & 10 & 1420 & $\begin{array}{l}\text { Necrosis intestinal } \\
\text { de } 10 \mathrm{~cm}\end{array}$ & $\begin{array}{l}\text { Resección del íleon } \\
\text { e ileostomía }\end{array}$ & 2 & 3 \\
\hline 7 & Femenino & 29 & 8 & 1050 & $\begin{array}{c}\text { Necrosis intestinal } \\
\text { de } 15 \mathrm{~cm} \text { y perforación }\end{array}$ & $\begin{array}{c}\text { Resección ileocólica } \\
\text { e ileostomía }\end{array}$ & 3 & 3 \\
\hline 8 & Masculino & 28 & 12 & 930 & $\begin{array}{c}\text { Necrosis intestinal } \\
\text { de } 15 \mathrm{~cm} \text { y perforación }\end{array}$ & $\begin{array}{l}\text { Resección del íleon } \\
\text { e ileostomía }\end{array}$ & 2 & 3 \\
\hline
\end{tabular}

$\mathrm{cm}$ : centimetros.

TABla 2: Características clinicas, puntaje de lesión tisular y de apoptosis de los pacientes del grupo con atresia ileal

\begin{tabular}{|c|c|c|c|c|c|c|c|}
\hline $\begin{array}{l}\text { Pacientes } \\
\text { del grupo } \\
\text { con atresi } \\
\text { ileal }\end{array}$ & $\begin{array}{ll}\text { s } & \text { Sexo } \\
\text { o } & \\
\text { ia } & \\
& \\
\end{array}$ & $\begin{array}{c}\text { Edad } \\
\text { gestacional } \\
\text { (en semanas) }\end{array}$ & $\begin{array}{c}\text { Edad al } \\
\text { momento de } \\
\text { la cirugía } \\
\text { (en días) }\end{array}$ & $\begin{array}{c}\text { Peso } \\
\text { (en gramos) }\end{array}$ & $\begin{array}{c}\text { Hallazgos durante } \\
\text { la cirugía y } \\
\text { procedimiento quirúrgico }\end{array}$ & $\begin{array}{l}\text { Puntaje } \\
\text { del grado de } \\
\text { lesión tisular }\end{array}$ & $\begin{array}{c}\text { Puntaje de } \\
\text { apoptosis }\end{array}$ \\
\hline 1 & Femenino & 32 & 3 & 1600 & Atresia ileal de tipo IIIa. Anastomosis íleo-ileal & 2 & 2 \\
\hline 2 & Masculino & 36 & 2 & 2200 & Atresia ileal de tipo II. Anastomosis íleo-ileal & 1 & 1 \\
\hline 3 & Masculino & 38 & 2 & 3100 & Atresia ileal de tipo II. Anastomosis íleo-ileal & 1 & 1 \\
\hline 4 & Femenino & 33 & 4 & 1540 & Atresia ileal múltiple. Dos anastomosis íleo-ileales & 3 & 3 \\
\hline 5 & Femenino & 40 & 2 & 3300 & Atresia ileal de tipo II. Anastomosis íleo-ileal & 1 & 1 \\
\hline 6 & Masculino & 38 & 2 & 2700 & Atresia ileal de tipo IIIa. Anastomosis íleo-ileal & 1 & 2 \\
\hline 7 & Femenino & 37 & 2 & 2750 & Atresia ileal de tipo I. Anastomosis íleo-ileal & 1 & 1 \\
\hline 8 & Masculino & 38 & 2 & 2930 & Atresia ileal de tipo II. Anastomosis íleo-ileal & 1 & 1 \\
\hline
\end{tabular}


en los genes apoptóticos y antiapoptótico se evaluaron mediante el método de matriz de RCP (PCR array). ${ }^{9}$ La expresión de proteínas se evaluó con la técnica de inmunohistoquímica. ${ }^{10}$

\section{Análisis estadístico}

El puntaje apoptótico y los grados de lesión tisular se evaluaron, a nivel estadístico, con la prueba de la U de Mann-Whitney. Para los estudios de transcripción de genes y expresiones de proteínas se utilizó la prueba t de Student. Un valor de $p<0,01$ se consideró estadísticamente significativo.

\section{RESULTADOS}

En las Tablas 1 y 2 se describen las características clínicas de los grupos con enterocolitis necrosante y los que presentaban atresia ileal. Los pacientes de este grupo tuvieron un peso significativamente mayor al del grupo con enterocolitis necrosante. Todos los pacientes con enterocolitis necrosante eran prematuros; su edad gestacional media al nacer era de $29,3 \pm 2,6$ semanas y su peso medio al momento de la cirugía era de $1171 \pm 321 \mathrm{~g}$. La mediana de la edad en el grupo con enterocolitis necrosante era de 12,5 días (7-20), mientras que en el grupo de atresia intestinal era de 2,3 días. ${ }^{2-4}$ Dos de los pacientes de este grupo eran prematuros y la edad gestacional media fue de $36,5 \pm 2,7$ semanas, con un peso medio al momento de la cirugía de $2515 \pm 666$ g. Las indicaciones para la cirugía en el grupo con enterocolitis necrosante fueron neumoperitoneo $(n=5)$ y fracaso del tratamiento médico asociado con dilatación persistente de asas en la radiografía $(n=2)$ o presencia de aire en el sistema venoso portal $(n=1)$. Todos los pacientes con enterocolitis necrosante tenían necrosis intestinal significativa que requerió resección intestinal e ileostomía durante la cirugía. En todos los pacientes del otro grupo se corrigió la atresia ileal mediante anastomosis íleo-ileal.

En la microscopía óptica de las muestras teñidas con hematoxilina-eosina, en las muestras obtenidas de seis pacientes con atresia ileal se observó separación entre el epitelio superficial y la lámina propria. En la muestra de un paciente se observó separación de la submucosa y en la de otro, separación de la submucosa y la lámina propria. Este último paciente era un recién nacido prematuro con atresia de tipo IV. En las muestras de cuatro pacientes con enterocolitis necrosante se observó separación grave de la submucosa y la lámina propria, edema en las capas submucosa y muscular y pérdida de la integridad epitelial. En los otros cuatro pacientes con enterocolitis necrosante era evidente la necrosis transparietal. En la Tabla 3 se muestran los puntajes del grado de lesión tisular según el grupo. Los puntajes de la lesión tisular eran significativamente más altos en el grupo con enterocolitis necrosante en comparación con el grupo de referencia $(3,3 \pm 0,8$ frente a $1,5 \pm 0,8 ; p<0,01$ ).

Entre los ocho pacientes con atresia ileal, se observó apoptosis leve en el epitelio superficial en siete y apoptosis que comprometía las vellosidades y las criptas en uno. En todas las muestras de los pacientes con enterocolitis necrosante se halló apoptosis que comprometía las vellosidades y las criptas (n: 4) o apoptosis transparietal (n: 4). En la Tabla 4 se describen los resultados de los puntajes de apoptosis según el grupo. Los puntajes medios de apoptosis fueron significativamente más altos en el grupo con enterocolitis necrosante que en el grupo con atresia intestinal $(3,5 \pm 0,5$ vs. $1,6 \pm 0,5 ; p<0,01)$.

La diferencia entre la expresión de los genes apoptóticos y antiapoptóticos entre ambos grupos se describe en la Tabla 5. El nivel de ARNm en los genes proapoptóticos (caspasa-3, caspasa-6, caspasa-7, BIRC2 y Bax) aumentó significativamente en el grupo con enterocolitis necrosante en comparación con el grupo de referencia $(p<0,01)$. El nivel de ARNm en el gen Bcl-2A1 (antiapoptótico) disminuyó significativamente en el grupo con enterocolitis necrosante a $(p<0,01)$. Sin embargo, no se observó una diferencia estadísticamente significativa en

TABLA 3: Grados de lesión tisular según el grupo

\begin{tabular}{|c|c|c|c|c|c|}
\hline Grupos & Grado 0 & Grado 1 & Grado 2 & Grado 3 & Grado 4 \\
\hline Grupo con enterocolitis necrosante $(n=8)$ & - & - & 2 & 3 & 3 \\
\hline Grupo de referencia $(n=8)$ & - & 6 & 1 & 1 & - \\
\hline
\end{tabular}

TABla 4: Puntajes de apoptosis según el grupo

\begin{tabular}{lcccc} 
Grupos & Puntaje 0 & Puntaje 1 & Puntaje 2 & Puntaje 3 \\
\hline Grupo con enterocolitis necrosante $(n=8)$ & - & - & - & 4 \\
Grupo de referencia $(n=8)$ & - & 5 & 2 & 4 \\
\hline
\end{tabular}


los niveles de ARNm de caspasa-1, caspasa-2, caspasa-9, Bad, Bcl- $\mathrm{X}_{\mathrm{L}}$ y Bcl-w entre ambos grupos.

En la Tabla 6 se muestran los valores de expresión de las proteínas. El porcentaje medio de expresión de las proteínas Bax y caspasa-3 era significativamente más alto en el grupo con enterocolitis necrosante en comparación con el grupo con atresia ileal.

\section{DISCUSIÓN}

En este estudio se demostró el incremento de la expresión de Bax (proapoptótico) y la disminución de la expresión de Bcl-2 (antiapoptótico). En otro estudio, se observaron niveles más elevados de proteína BNIP3 en las muestras del íleon obtenidas de recién nacidos sometidos a una resección quirúrgica, y los autores propusieron que el aumento de la proteína BNIP3 relacionada con la apoptosis es un posible mecanismo asociado con la apoptosis de enterocitos observada en la enterocolitis necrosante. ${ }^{6}$ Más recientemente, se ha identificado el receptor inmunológico centinela, el receptor de tipo Toll 4 (TLR4); se cree que la activación de este receptor por parte del lipopolisacárido bacteriano es la responsable directa del aumento de las tasas de apoptosis y la deficiente cicatrización de la mucosa. ${ }^{11,12}$ En un estudio de investigación en ratones con deficiencia en la señalización de TLR4 se demostró la prevención de la apoptosis intestinal inducida por el LPS y una reducción de la incidencia de enterocolitis necrosante. ${ }^{11}$ Asimismo, se ha demostrado que la glutamina reduce la expresión del receptor de tipo Toll 2 (TLR2) y del TLR4 y protege el intestino de las ratas recién nacidas prematuras con enterocolitis necrosante. ${ }^{12}$ Estos estudios proporcionan una justificación para investigar de qué manera se produce la regulación de la apoptosis de enterocitos dentro del intestino de los recién nacidos durante la aparición de la enterocolitis necrosante.

En este estudio, investigamos la expresión de los genes proapoptóticos y antiapoptóticos en el intestino de los recién nacidos con enterocolitis necrosante aguda. De manera coincidente con informes previos, se detectaron niveles elevados de lesión tisular y apoptosis extensa de los enterocitos de los recién nacidos con enterocolitis necrosante en comparación con los pacientes del grupo de referencia, que tenían atresia intestinal. ${ }^{2,6,7,13}$ En las muestras de los pacientes con atresia ileal que utilizamos como referencia se observaron cierto grado de lesión tisular leve y apoptosis. Podría argumentarse que tal vez los tejidos de los pacientes con atresia intestinal no sean normales. Sin embargo, obtuvimos las muestras de una porción intestinal de aspecto sumamente viable y para la cual se preveía un funcionamiento normal. Los cambios leves observados en los pacientes con atresia ileal tal vez sean un reflejo de la lesión mucosa, que podría ser consecuencia de la dilatación intestinal prolongada o la manipulación intestinal durante la cirugía. El aumento de los puntajes de lesión tisular y apoptosis observado en uno de los pacientes podría estar directamente relacionado con la atresia intestinal de tipo IV, un tipo más grave que en el resto, o el retraso de la cirugía, que

TABLA 5: Cambio en la expresión de los genes proapoptóticos y antiapoptóticos

\begin{tabular}{llc}
\hline Genes & Función & Cambio en la expresión de los genes \\
\hline Caspasa-1 & Apoptótica, cisteína peptidasa & $+0,68 \pm 0,10$ \\
Caspasa-2 & Apoptótica, cisteína peptidasa & $+1,15 \pm 0,07$ \\
Caspasa-3 & Apoptótica, cisteína peptidasa & $+6,70 \pm 1,06^{*}$ \\
Caspasa-6 & Apoptótica, cisteína peptidasa & $+5,33 \pm 1,60^{*}$ \\
Caspasa-7 & Apoptótica, cisteína peptidasa & $+10,52 \pm 2,12^{*}$ \\
Caspasa-9 & Apoptótica, cisteína peptidasa & $+1,21 \pm 0,02$ \\
BCL2A1 & Proteína A1 relacionada con BCL2, antiapoptótica & $-5,42 \pm 1,32^{*}$ \\
BIRC2 & Proteína que contiene dos repeticiones de IAP baculoviral, apoptótica & $+5,20 \pm 1,16^{*}$ \\
BAX & Proteína X asociada a Bcl-2, apoptótica & $+27,24 \pm 5,16^{*}$
\end{tabular}

$\mathrm{n}=8$, media $\pm \mathrm{SDv},{ }^{*} \mathrm{p}<0,01$

TABLA 6: Expresión de Bax y caspasa-3 en el tejido intestinal

\begin{tabular}{lccc|ccc}
\hline & \multicolumn{3}{c}{ Grupo de referencia } & \multicolumn{3}{c}{ Enterocolitis necrosante } \\
\hline & Patólogo 1 & Patólogo 2 & ${ }^{*}$ Promedio & Patólogo 1 & Patólogo 2 & ${ }^{*}$ Promedio \\
\hline Expresión de caspasa-3 & $34,33 \pm 4,73$ & $32,67 \pm 4,16$ & $33,5 \pm 4,44$ & $93,33 \pm 5,69$ & $86,67 \pm 7,57$ & $* * 90,00 \pm 6,63$ \\
Expresión de Bax & $26,02 \pm 3,53$ & $29,42 \pm 3,24$ & $27,72 \pm 3,39$ & $95,33 \pm 6,96$ & $98,71 \pm 8,69$ & $* * 97,02 \pm 7,66$ \\
\hline
\end{tabular}

*\% de expresión ** $\mathrm{p}<0,01$ 
se realizó a los 4 días de vida del paciente.

En las muestras de los tejidos de los recién nacidos con enterocolitis necrosante se detectaron un incremento de la expresión de los genes apoptóticos (caspasa-3, caspasa-6, caspasa-7, BIRC2 y Bax) y una disminución de la expresión del gen antiapoptótico (Bcl-2A1). El porcentaje medio de expresión de las proteínas Bax y caspasa-3 era significativamente más alto en el grupo con enterocolitis necrosante frente al grupo con atresia ileal. No se observaron diferencias estadísticamente significativas en la expresión de Bad, Bcl-xL y Bcl-w al comparar los intestinos de los pacientes con enterocolitis necrosante y con atresia ileal. Estos resultados de nuestro estudio coinciden con el estudio de investigación sobre enterocolitis necrosante neonatal previo. ${ }^{5}$ En conjunto, las proteínas Bcl-2 y Bax componen un reóstato celular que regula la transición celular hacia la apoptosis o que se aparta de esta. ${ }^{3,14}$ Nuestros datos que demuestran un aumento de la expresión de los genes caspasa-3, caspasa- 6 y caspasa-7 y de la expresión de la proteína caspasa-3 coinciden con los resultados de un estudio previo, que indican que la suplementación con un inhibidor de la pancaspasa normaliza las tasas de apoptosis y conlleva a una reducción de la incidencia de enterocolitis necrosante en un modelo de ratas recién nacidas con enterocolitis necrosante. ${ }^{2}$

Las modalidades de tratamiento que podrían modular la proporción de Bax:Bcl-2 a favor de la supervivencia celular intestinal previenen el avance de la apoptosis y la aparición de enterocolitis necrosante. El factor de crecimiento epidérmico (FCE) es uno de los factores de crecimiento que se encuentra en la leche materna de manera natural. Clark y col. demostraron que, en ratas recién nacidas con enterocolitis necrosante, la suplementación de la leche con FCE redujo notablemente las proporciones de Bax:Bcl-2 en el ARNm y las proteínas y disminuyó drásticamente la apoptosis. ${ }^{5,15} \mathrm{En}$ ensayos clínicos preliminares se utilizó FCE recombinante intravenoso en recién nacidos con diagnóstico de enterocolitis necrosante, que mejoró la reparación del epitelio intestinal al reducir la actividad proliferativa de las criptas. ${ }^{15}$ Los efectos beneficiosos de la suplementación con FCE en los recién nacidos podrían depender de la estimulación de la cicatrización de la barrera mucosa intestinal y la consiguiente prevención de la enterocolitis necrosante.

\section{CONCLUSIÓN}

Según nuestros datos en recién nacidos, la alteración del equilibrio entre la expresión de Bax (proapoptótico) y la expresión de Bcl-2A1 (antiapoptótico) puede ser un posible mecanismo de la patogenia de la enterocolitis necrosante. Nuestro estudio constituye la base de estudios futuros que deberán realizarse para comprender los mecanismos que causan la alteración del equilibrio entre la expresión de los genes proapoptóticos y antiapoptóticos y para diseñar futuras estrategias terapéuticas o preventivas para la enterocolitis necrosante mediante la modificación de la apoptosis.

\section{REFERENCIAS}

1. Dominguez KM, Moss RL. Necrotising enterocolitis. Clin Perinatol 2012;39(2):387-401.

2. Jilling T, Lu J, Jackson M, Caplan MS. Intestinal Epithelial Apoptosis Initiates Gross BowelNecrosis in an Experimental Rat Model of Neonatal Necrotising Enterocolitis. Pediatr Res 2004;55(4):622-9.

3. Khailova L, Mount Patrick SK, Arganbright KM, Halpern $\mathrm{MD}$, et al. Bifidobacterium bifidum reduces apoptosis in the intestinal epithelium in necrotizing enterocolitis. Am J Physiol Gastrointest Liver Physiol 2010;299(5):G1118-27.

4. Maynard AA, Dvorak K, Khailova L, Dobrenen H, et al. Epidermal growth factor reduces autophagy in intestinal epithelium and in the rat model of necrotizing enterocolitis. Am J Physiol Gastrointest Liver Physiol 2010;299(3):G614-22.

5. Clark JA, Lane RH, MacLennan NK, Holubec H, et al. Epidermal growth factor reduces intestinal apoptosis in an experimental model of necrotizing enterocolitis. Am J Physiol Gastrointest Liver Physiol 2005;288(4):G755-62.

6. Zamora R, Vodovotz Y, Betten B, Wong C, et al. Intestinal and hepatic expression of BNIP3 in necrotizing enterocolitis: regulation by nitric oxide and peroxynitrite. Am J Physiol Gastrointest Liver Physiol 2005;289(5):G822-30.

7. Halpern MD, Clark JA, Saunders TA, Doelle SM, et al. Reduction of experimental necrotizing enterocolitis with anti-TNF- . Am J Physiol Gastrointest Liver Physiol 2006; 290(4):G757-64.

8. Halpern MD, Weitkamp JH, Mount Patrick SK, Dobrenen $\mathrm{HJ}$, et al. Apical sodium-dependent bile acid transporter upregulation is associated with necrotizing enterocolitis. Am I Physiol Gastrointest Liver Physiol 2010;299(3):G623-31.

9. Bagriacik EU, Yaman M, Haznedar R, Sucak G, Delibasi T. TSH-induced gene expression involves regulation of selfrenewal and differentiation-related genes in human bone marrow-derived mesenchymal stem cells. J Endocrinol 2012;212(2):169-78.

10. Charafe-Jauffret E, Tarpin C, Bardou VJ, Bertucci F, et al. Immunophenotypic analysis of inflammatory breast cancers: identification of an 'inflammatory signature'. J Pathol 2004; 202(3):265-73.

11. Leaphart CL, Cavallo J, Gribar SC, Cetin S, et al. A critical role for TLR4 in the pathogenesis of necrotizing enterocolitis by modulating intestinal injury and repair. I Immunol 2007;179(7):4808-20.

12. Zhou W, Li W, Zheng XH, Rong X, Huang LG. Glutamine down regulates TLR-2 andTLR-4 expression and protects intestinal tract in preterm neonatal rats with necrotizing enterocolitis. J Pediatr Surg 2014;49(7):1057-63.

13. Ford H,Watkins $S$, ReblockK, et al. The role of inflammatory cytokines and nitric oxide in the pathogenesis of necrotizing enterocolitis. J Pediatr Surg 1997;32(2):275-82.

14. Czabotar PE, Lessene G, Strasser A, Adams JM. Control of apoptosis by the BCL-2 protein family: implications for physiology and therapy. Nat Rev Mol Cell Biol 2014;15(1): 49-63.

15. Coursodon CF, Dvorak B. Epidermal growth factor and necrotizing enterocolitis. Curr Opin Pediatr 2012;24(2):160-4 


\section{Nivel de participación social, recreativa, deportiva e independencia de adolescentes y adultos jóvenes con osteogénesis imperfecta Osteogenesis imperfecta: Level of independence and of social, recreational and sports participation among adolescents and youth}

Dra. Mercedes Rodríguez Celin ${ }^{a}$ y Dra. Virginia Fano ${ }^{a}$

\section{RESUMEN}

Introducción. La osteogénesis imperfecta comprende un grupo heterogéneo de síndromes del tejido conectivo, que produce fragilidad ósea, amplia variabilidad clínica con diversos grados de discapacidad motora.

Objetivos. Describir el nivel de independencia, la participación social, recreativa y deportiva en adolescentes con osteogénesis imperfecta.

Población y métodos. Estudio descriptivo-analítico y transversal en pacientes con osteogénesis imperfecta mayores de 15, atendidos en el Consultorio de Displasias Esqueléticas del Hospital "Prof. Dr. Juan P. Garrahan" (mayo de 2013-diciembre de 2014). Encuesta autoadministrada. El déficit de talla fue una variable indicadora de gravedad.

Resultados. 18 pacientes; edad: 19,17 ( $\pm 3,4 \mathrm{sDE})$; $83 \%$, con formas moderas-graves; mediana de talla: $-7,9$ sDE. El $50 \%$ usaba silla de ruedas.

Promedio de años de estudio: 12,2; 56\% participaba en actividades deportivas; $78 \%$, en actividades recreativas y sociales. Alto nivel de independencia.

Encontramos correlación entre el déficit de talla y el uso de silla de ruedas $(\mathrm{r}:-0,77)$ y entre el déficit de talla y la participación deportiva (r: 0,66$)$. No encontramos correlación con años de estudio (r: -0,15), participación social $(\mathrm{r}:-0,22)$ o recreativa (r: 0,35).

Palabras clave: osteogénesis imperfecta, adolescente, participación social, actividades recreativas.

http:/ /dx.doi.org/10.5546/aap.2016.248

a. Servicio de Crecimiento y Desarrollo, Clínica de Displasias Esqueléticas, Hospital de Pediatría "Prof. Dr. Juan P. Garrahan", Ciudad Autónoma de Buenos Aires.

Correspondencia: Dra. Mercedes Rodríguez Celin mercedesrodriguezcelin@gmail.com

Financiamiento: Ninguno.

Conflicto de intereses: Ninguno que declarar.

Recibido: 3-11-2015

Aceptado: 11-1-2016

\section{INTRODUCCIÓN}

La osteogénesis imperfecta (OI) es un grupo heterogéneo de síndromes del tejido conectivo, que produce fragilidad ósea. ${ }^{1}$ Esta enfermedad está etiológicamente relacionada, en forma directa o indirecta, con el colágeno tipo $\mathrm{I}^{2}{ }^{2}$ con una prevalencia de 1 en 12 000-15000 recién nacidos $(\mathrm{RN}){ }^{3}$

Presenta una amplia variabilidad clínica. La clasificación original de 1979 de Sillence en tipo I, II, III y IV ha sido modificada por Van Dijk y Sillence en 2014 de acuerdo con la gravedad clínica en leve, moderada, grave y extremadamente grave. ${ }^{1}$ En las formas graves, las fracturas suelen ser múltiples, presentarse desde antes del nacimiento y llevar a deformidades esqueléticas y complicaciones. Otros signos frecuentes son grados variables de baja estatura, alteración dentaria e hipoacusia. Esta enfermedad no está asociada con afectación intelectual. ${ }^{4}$

No existe un único esquema terapéutico, sino que el tratamiento debe adecuarse en forma individualizada y consensuada entre el equipo multidisciplinario, el paciente y su familia. ${ }^{3,5}$

En un estudio realizado en 2011 en el Hospital Shriners de Canadá, que asiste a pacientes con OI, se realizó una encuesta en la que se evaluó el nivel de participación social, recreativa, deportiva, así como el nivel de independencia en 24 pacientes adolescentes-adultos jóvenes con OI.

Creemos que tener un panorama más amplio en estos aspectos, en nuestro grupo de pacientes con OI, puede ayudarnos a mejorar las estrategias terapéuticas.

\section{OBJETIVO}

Describir el nivel de independencia, la participación social, recreativa y deportiva en jóvenes con OI.

\section{POBLACIÓN Y MÉTODOS}

Se realizó un estudio descriptivo-analítico y transversal. 
Se evaluaron todos los pacientes con OI, mayores de 15 años, que concurrieron al Consultorio de Displasias Esqueléticas del Hospital "Prof. Dr. Juan P. Garrahan" (mayo de 2013 y diciembre de 2014). Se evaluaron variables clínicas: edad, sexo, tipo de OI, zT. Se utilizó la última clasificación publicada por Van Dijk. ${ }^{1}$ Se invitó a todos los pacientes a responder una encuesta autoadministrada, que es la traducción de la encuesta desarrollada en el Hospital Shriners de Canadá. ${ }^{4}$ La traducción estuvo a cargo de una autora; su comprensión se probó en 3 pacientes $y$, posteriormente, se realizaron mínimas correcciones gramaticales. Antes de responder la encuesta, los pacientes aceptaron oralmente su participación.

La encuesta incluyó 20 preguntas. Las primeras 17 y la 19 eran sobre desarrollo académico-laboral, vivienda, transporte, vínculo con el Hospital y sobre participación social, recreativa y deportiva. Las preguntas eran cerradas con opciones únicas o múltiples de respuesta según cada pregunta. La pregunta 18 evaluaba 15 ítems sobre movilidad, autocuidado y actividades de la vida diaria. Estos ítems se puntuaron de 1 a 4 (desde requerir máxima asistencia a independencia) y fueron seleccionados de dos diferentes herramientas: el Functional Independence Measure (FIM) y el Instrumental Activities Measure (IAM). ${ }^{6}$ El FIM evalúa la disfunción en áreas físicas y cognitivas. El IAM fue desarrollado como complemento del FIM para proveer información sobre el nivel de independencia. La pregunta 20 era abierta sobre planes futuros. Se adjunta una copia del cuestionario en el Anexo (en formato electrónico).

Tomamos el zT como variable indicadora de gravedad (a mayor déficit, mayor gravedad). ${ }^{1,7}$ Para las correlaciones, el zT se consideró como variable independiente. Se buscó correlación con variables seleccionadas de la encuesta: uso de silla de ruedas, participación social (participación en grupos religiosos, visita al centro comercial o ver películas con amigos, etc.), deportiva (participación en caminatas, natación, básquet, etc.), recreativa (participación en actividades de lectura, manualidades, computadora, etc.) y número de años de estudio cumplidos (se consideraron años de estudio cumplidos a partir de la escolaridad obligatoria: sala de 5 años).

\section{Análisis estadístico}

Los datos se resumieron mediante estadísticos de tendencia central y dispersión según correspondiera. Para correlacionar el zT con distintas variables seleccionadas obtenidas en la encuesta, se utilizó el coeficiente de Spearman para variables no paramétricas.

\section{RESULTADOS}

\section{Características generales de la muestra}

Todos los pacientes aceptaron responder el cuestionario y lo hicieron en forma autoadministrada, excepto un paciente, que requirió ayuda por limitación motora.

Se incluyeron 18 pacientes con osteogénesis imperfecta mayores de 15 años (11 varones); la edad media fue de 19,17 $( \pm 3,4 \mathrm{sDE})$.

El 83\% tenía formas moderadas-graves y $17 \%$, formas leves. La mediana de zT fue de $-7,9 \mathrm{sDE}$ $(-14,68 /+1,5 \mathrm{sDE})$.

\section{Análisis del cuestionario}

Para movilizarse, $50 \%$ usaba silla de ruedas todo el tiempo, $17 \%$ combinaba el uso de la silla de ruedas con la deambulación asistida y 33\% deambulaba de modo independiente.

Con respecto a la educación, ocupación, vivienda y transporte, encontramos que el promedio de años de estudio fue de 12,2 años y $78 \%$ se encontraba estudiando. De los pacientes mayores de 18 años (11 pacientes), 36\% se encontraba trabajando. Al $69 \%$ le hubiera gustado trabajar; el $24 \%$ creía que para ello requería adaptaciones. El 89\% vivía en casa familiar. El $78 \%$ utilizaba transporte público, pero solo el $29 \%$ lo hacía en forma independiente. Solo 1 paciente manejaba su auto. El 50\% era pasajero del auto familiar.

La participación social, deportiva y recreativa se informa en la Tabla 1.

Con respecto a la percepción del estado de salud, a su capacidad de manejo de la enfermedad y a la comunicación con el equipo médico, así como su conexión con el sistema de salud fuera del Hospital pediátrico, encontramos que el 55\%

TABla 1. Participación en actividades deportivas, sociales y recreativas en adolescentes con osteogénesis imperfecta (N: 18)

\begin{tabular}{lccc}
$\begin{array}{l}\text { Participa } \\
\text { en actividad }\end{array}$ & Regularmente & Ocasionalmente & $\begin{array}{c}\text { Nunca } \\
\text { participa }\end{array}$ \\
\hline Deportiva & $39 \%$ & $17 \%$ & $44 \%$ \\
Social & $50 \%$ & $28 \%$ & $22 \%$ \\
Recreativa & $67 \%$ & $11 \%$ & $22 \%$ \\
\hline
\end{tabular}


de los pacientes refería que su salud era muy buena-excelente, el 39\% decía que era buena y solo un paciente decía que era regular. El 66\% recibía seguimiento médico cercano a su domicilio y el 50\% refería que ese médico sabía manejar la enfermedad. El $94 \%$ se sentía capacitado para manejarla; sin embargo, el $61 \%$ solo a veces hablaba de sus necesidades con sus médicos y el $43 \%$ siempre tomaba sus decisiones terapéuticas.

Al preguntarles a los pacientes evaluados en qué medida el Hospital pediátrico había colaborado para que se sintieran saludables e independientes, el 95\% de los pacientes refirieron que había colaborado en gran medida. El 61\% de los pacientes respondieron que los había ayudado en gran medida a tomar sus propias decisiones, pero solo un $46 \%$ refirieron que los había ayudado en gran medida a encontrar un hospital para su atención en la adultez.

El nivel de independencia referido con respecto a movilidad, autocuidado y actividades de la vida diaria se informa en la Tabla 2.

Los participantes fueron invitados a compartir algún plan para el futuro y todos menos un paciente lo expresaron por escrito. Dentro de los planes futuros más frecuentes, se encontraron el deseo de iniciar o finalizar una carrera universitaria, trabajar y tener una familia.

\section{Correlación entre el déficit de estatura y las distintas variables}

Como variable clínica indicadora de gravedad, se tomó el zT, medido en puntaje z. Encontramos una correlación negativa entre el zT y la necesidad del uso de la silla de ruedas (r: 0,77 ). El grupo que tenía mayor participación en deportes era el que tenía menor compromiso de estatura (r: 0,66). No encontramos correlación entre el zT y los años de estudio $(\mathrm{r}: 0,15)$, participación social $(\mathrm{r}:-0,22)$ y recreativa (r: 0,35$)$.

\section{DISCUSIÓN}

Como debilidad de este trabajo, debemos mencionar que la encuesta no atravesó los pasos de adaptación transcultural y que la muestra de pacientes no fue grande, pero, dado que es una enfermedad poco frecuente, creemos que igualmente puede aportar datos útiles.

En el grupo de pacientes, se observó que, en diferente medida, $78 \%$ participaba en actividades sociales y recreativas, y no encontramos correlación entre el zT y la frecuencia de dicha participación. Los datos publicados por Montpetit ${ }^{4}$ son similares a los nuestros: no encontró diferencias de participación social ni recreativa entre los distintos tipos de OI. En comparación con las actividades mencionadas, la

\begin{tabular}{lcccc}
\hline & Independiente & $\begin{array}{c}\text { Necesita ayuda } \\
\text { mínima }\end{array}$ & $\begin{array}{c}\text { Necesita ayuda } \\
\text { moderada }\end{array}$ & $\begin{array}{c}\text { Necesita ayuda } \\
\text { máxima }\end{array}$ \\
\hline Alimentación & 16 & 1 & 1 & 0 \\
Aseo personal & 14 & 3 & 1 & 0 \\
Baño & 15 & 1 & 1 & 1 \\
Vestir la parte superior & 18 & 0 & 0 & 0 \\
Vestir la parte inferior & 16 & 0 & 1 & 5 \\
Traslado al baño & 11 & 1 & 1 & 5 \\
Traslado a la ducha & 11 & 2 & 0 & 3 \\
Traslado a la silla & 11 & 3 & 1 & 5 \\
Traslado al auto & 10 & 2 & 1 & 1 \\
Movilidad fuera del hogar & 14 & 1 & 2 & 6 \\
Preparación de comidas simples & 15 & 1 & 1 & 2 \\
Cocina y lavado de vajilla & 9 & 2 & 1 & 5 \\
Ir de compras & 14 & 1 & 1 & 5 \\
Limpieza & 9 & 3 & 1 & \\
Lavandería & 10 & 1 & 2 & 5 \\
\hline
\end{tabular}


participación deportiva fue menor, coincidente con lo publicado por Montpetit, que encontró menor participación deportiva en las formas graves. $^{4}$

Los niveles de independencia reflejados en la movilidad, el autocuidado y las actividades de la vida diaria son altos. Las dificultades son coincidentes con las encontradas en los pacientes con OI tipo III en la publicación referida. ${ }^{4}$

$\mathrm{Cole}^{8}$ sugirió que la OI, a pesar de asociarse con un intelecto normal, podría afectar los logros académicos por tratarse de una enfermedad con importante compromiso físico, presencia de dolor y discapacidad motora. En nuestro grupo, no encontramos correlación entre cantidad de años de estudio completados y gravedad, lo que concordó con los altos niveles de logros educativos en otras poblaciones con OI reportados por Montpetit ${ }^{4} \mathrm{y}$ Widmann. ${ }^{9}$

En la revisión realizada por Thompson ${ }^{10}$ en adultos con displasias esqueléticas, se describieron distintos grados de aislamiento social y su influencia en el nivel educativo alcanzado. Dado que, en nuestro estudio, el 22\% refirió que nunca participaba en actividades sociales, este aspecto debe considerarse con atención.

Queda para estudios futuros ver cómo los niveles de independencia y participación pueden afectar la calidad de vida en pacientes con OI. ${ }^{11,12}$

\section{Agradecimientos}

A la Dra. Mariana del Pino por la lectura crítica del artículo y los aportes realizados.

\section{REFERENCIAS}

1. Van Dijk FS, Sillence DO. Osteogenesis imperfecta: clinical diagnosis, nomenclature and severity assessment. Am J Med Genet A 2014;164A(6):1470-81.

2. Marini JC, Blissett AR. New genes in bone development: what's new in osteogenesis imperfecta. J Clin Endocrinol Metab 2013;98(8):3095-103.

3. Glorieux F. Guide to Osteogenesis Imperfecta for pediatricians and family practice physicians. Berhesda: National Institute of Health; 2007.

4. Montpetit K, Dahan-Oliel N, Ruck-Gibis J, Fassier F, et al. Activities and participation in young adults with osteogenesis imperfecta. J Ped Rehabil Med 2011;4(1):13-22.

5. Fano V, Rodriguez Celin M, del Pino M, Buceta S, et al. Osteogénesis imperfecta. Evaluación clínica, funcional y multidisciplinaria de 65 pacientes. An Pediatr (Barc) 2010;72(5):324-30.

6. Grimby G, Andrén E, Holmgren E, Wright B, et al. Structure of a combination of Functional Independence Measure and Instrumental Activity Measure Items in community-living persons: a study of individuals with cerebral palsy and spina bifida. Arch Phys Med Rehabil 1996;77(11):1109-14.

7. Ben Amor IM, Glorieux FH, Rauch F. Genotype-phenotype correlations in autosomal dominant osteogenesis imperfecta. J Osteoporos 2011;2011:540178.

8. Cole DE. Psychosocial aspects of osteogenesis imperfecta: an update. Am J Med Genet 1993;45(2):207-11.

9. Widmann RF, Laplaza FJ, Bitan FD, Brooks CE, etal. Quality of life in osteogenesis imperfecta. Int Orthop 2002;26(1):3-6.

10. Thompson S, Shakespeare T, Wright MJ. Medical and social aspects of the life course for adults with a skeletal dysplasia: a review of current knowledge. Disabil Rehabil 2008;30(1):1-12.

11. Fano V, Del Pino M, Rodríguez Celin M, Buceta S, et al. Osteogénesis imperfecta: estudio de la calidad de vida en los niños. Arch Argent Pediatr 2013;111(4):328-31.

12. Hill CL, Baird WO, Walters SJ. Quality of life in children and adolescents with Osteogenesis Imperfecta: a qualitative interview based study. Health Qual Life Outcomes 2014;12:54. 


\section{ANEXO}

Nombre y apellido:

Fecha de nacimiento:

Historia clínica $\mathrm{N}^{\mathrm{o}}$ :

Teléfono de contacto:

Fecha de consulta:

\section{CUESTIONARIO}

1) ¿Estás estudiando este año?

No.

Sí.

Año de escolaridad:

Tipo de educación (común, especial, domiciliaria):

¿Repetiste o perdiste algún año? Por favor, describí:

2) ¿Completaste cursos fuera de la escuela?

No.

Sí. Por favor, describí:

3.a) ¿Estás trabajando con sueldo?

No.

De 1 a 10 horas por semana.

De 11 a 25 horas por semana.

De 26 a 40 horas por semana.

Por favor, describí qué hacés en tu trabajo:

3.b) Si no trabajás, ¿te gustaría trabajar?

Sí.

No.

¿Estás buscando trabajo?

Sí.

No.

3.c) ¿Qué te ayudaría para trabajar?

El transporte.

Adaptaciones especiales.

Mayor educación o entrenamiento.

Superar el miedo a trabajar.

Que mis padres me permitieran hacerlo.

4) ¿Hiciste trabajos comunitarios (alguna actividad laboral sin remuneración, realizada en grupo para el bien de la comunidad)?

No.

De 1 a 10 horas por semana.

De 11 a 25 horas por semana.

De 26 a 40 horas por semana.

Por favor, describí:

5) ¿Cómo son las características del lugar donde vivís?

Casa familiar.

Departamento supervisado. 
Con amigos.

Con la pareja.

Otras. Por favor, describí:

6) ¿Participás en actividades deportivas (tales como caminar, acampar, nadar, jugar al básquet u otras)?

Nunca.

Ocasionalmente (1 o 2 veces por mes).

Regularmente (1 o más veces por semana).

Por favor, describí:

7) ¿Participás de actividades sociales fuera de tu casa (grupos religiosos, visitas a centros comerciales con amigos, ver películas con amigos, etc.)?

Nunca.

Ocasionalmente (1 o 2 veces por mes).

Regularmente (1 o más veces por semana).

Por favor, describí:

8) ¿Participás en actividades recreativas (lectura, manualidades, actividades con computadora)?

Nunca.

Ocasionalmente (1 o 2 veces por mes).

Regularmente (1 o más veces por semana).

Por favor, describí:

9) ¿Cómo viajas en tu comunidad?

Manejás tu propio auto.

Sos pasajero en el auto familiar.

Usás un transporte de servicio especial.

Usás el transporte público.

Si usás transporte público, indicá cómo lo utilizás:

En forma independiente (no necesito ayuda).

Asistencia mínima (necesito mínima ayuda).

Asistencia moderada (necesito moderada ayuda).

Asistencia máxima (necesito mucha ayuda).

10) En general, ¿cómo dirías que es tu salud?

Excelente.

Muy buena.

Buena.

Regular.

Pobre.

11) ¿Recibís seguimiento médico cercano a tu domicilio?

No. Por favor, comentá:

Sí. Por favor, describí:

Médico familiar.

Traumatólogo.

Otro.

¿Cuándo fue tu última visita?

12) ¿Sabe ese doctor cómo manejar esa enfermedad?

Sí.

No.

Por favor, describí: 
13) ¿Estás capacitado para cuidarte en relación con tu enfermedad, la osteogénesis imperfecta? Sí.

No. Por favor, comentá:

14) ¿Hablás con tus doctores sobre tus necesidades?

Todo el tiempo.

A veces.

Nunca.

15) ¿Tomás tus propias decisiones acerca de tu plan terapéutico?

Todo el tiempo.

A veces.

Nunca.

16) Para movilizarte:

Usás silla de ruedas todo el tiempo.

Usás una combinación de silla de ruedas y caminar.

Caminás con alguna ayuda todo el tiempo.

Caminás sin ayuda todo el tiempo.

17) ¿Qué necesitarías para ayudar a aumentar tu independencia?

Mejoras en el transporte.

Aprender a manejar.

Educación.

Una asistente para el cuidado personal.

Modificación en la casa o en el vehículo.

Ayuda para conseguir trabajo.

Ayuda para manejar tu condición de salud.

Participación comunitaria.

Grupo de ayuda.

Más experiencia para tomar decisiones.

Nada.

Otras:

18) Marcá tu nivel de independencia: (Tabla)

Independiente Necesita ayuda Necesita ayuda Necesita ayuda mínima

moderada

máxima

1. Alimentación (uso de cubiertos y vaso).

2. Aseo personal (peinarse, lavado de

dientes, lavado de cara y manos).

3. Baño (lavado y secado del cuerpo).

4. Vestir la parte superior del cuerpo (remera, abotonarse la chaqueta).

5. Vestir la parte inferior del cuerpo (pantalones, medias, zapatos, ropa interior).

6. Traslado al baño (sentarse en el inodoro).

7. Traslado a la ducha (meterse en la ducha).

8. Traslado a la silla (sentarse en la silla).

9. Traslado al auto (sentarse en el auto). 
Independiente Necesita ayuda Necesita ayuda Necesita ayuda mínima moderada máxima

10. Movilidad fuera del hogar (caminar o usar silla de ruedas fuera del lugar de residencia).

11. Preparación de comida simple (hacerse un sándwich, hacer una taza de té o café).

12. Cocinar (preparación de comida para

1 o 2 personas, incluido el lavado de platos).

13. Ir de compras (ir a los negocios,

elegir artículos, llevar los artículos a casa).

14. Limpieza (hacer las camas, aspirar, orden diario de la casa).

15. Lavandería (clasificación, uso de lavarropas, doblar la ropa).

19) Por favor, decinos en qué forma te ayudó el Hospital Garrahan para lo siguiente:

Estar saludable y ser independiente.

Encontrar un lugar para tu atención como adulto

Aprender a tomar tus propias decisiones.

20) ¿Podés compartir con nosotros algunos de tus planes futuros?. 